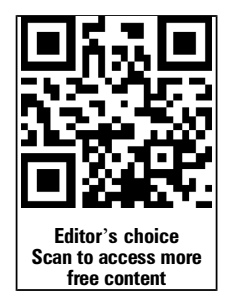

- Additional material is published online only. To view please visit the journal online (http://dx.doi.org/10.1136/jech2015-205657).

For numbered affiliations see end of article.

\section{Correspondence to} J Jaime Miranda, CRONICAS Center of Excellence in Chronic Diseases, Universidad Peruana Cayetano Heredia, Armendariz 497, 2nd Floor, Miraflores, Lima 18, Peru; jaime.miranda@upch.pe

Received 19 February 2015 Revised 27 March 2015 Accepted 24 April 2015 Published Online First 18 May 2015

\title{
Migration, urbanisation and mortality: 5-year longitudinal analysis of the PERU MIGRANT study
}

\author{
Melissa S Burroughs Pena, ${ }^{1,2}$ Antonio Bernabé-Ortiz, ${ }^{1}$ Rodrigo M Carrillo-Larco, ${ }^{1}$ \\ Juan F Sánchez, ${ }^{3}$ Renato Quispe, ${ }^{1}$ Timesh D Pillay, ${ }^{1,4}$ Germán Málaga, ${ }^{1,5}$ \\ Robert H Gilman, ${ }^{1,6,7}$ Liam Smeeth, ${ }^{1,8}$ J Jaime Miranda ${ }^{1,5}$
}

\section{ABSTRACT}

Objective To compare all-cause and cause-specific mortality among 3 distinct groups: within-country, ruralto-urban migrants, and rural and urban dwellers in a longitudinal cohort in Peru.

Methods The PERU MIGRANT Study, a longitudinal cohort study, used an age-stratified and sex-stratified random sample of urban dwellers in a shanty town community in the capital city of Peru, rural dwellers in the Andes, and migrants from the Andes to the shanty town community. Participants underwent a questionnaire and anthropomorphic measurements at a baseline evaluation in 2007-2008 and at a follow-up visit in 2012-2013. Mortality was determined by death certificate or family interview.

Results of the 989 participants evaluated at baseline, $928(94 \%)$ were evaluated at follow-up (mean age 48 years; $53 \%$ female). The mean follow-up time was

5.1 years, totalling 4732.8 person-years. In a multivariable survival model, and relative to urban dwellers, migrant participants had lower all cause mortality ( $\mathrm{HR}=0.30 ; 95 \% \mathrm{Cl} 0.12-0.78$ ), and both the migrant $(\mathrm{HR}=0.07 ; 95 \% \mathrm{Cl} 0.01-0.41)$ and rural (HR $=0.06 ; 95 \% \mathrm{Cl} 0.01-0.62)$ groups had lower cardiovascular mortality.

Conclusions Cardiovascular mortality of migrants remains similar to that of the rural group, suggesting that rural-to-urban migrants do not appear to catch up with urban mortality in spite of having a more urban cardiovascular risk factor profile.

\section{INTRODUCTION}

Urbanisation is rapidly occurring in low-income and middle-income countries (LMIC) throughout the world, particularly in Latin America. Within-country migration from rural communities to urban centres has impacted the lives of many individuals, particularly those of low socioeconomic status who are seeking better employment and educational opportunities. However, many migrants find themselves relocating to urban slums to live among a population that often lacks the infrastructure and access to public services of the more affluent urban communities. ${ }^{1}$ Urban lifestyles often include increased environmental exposures, stress, high-fat and high-calorie diets, and low physical activity, increasing the risk of chronic diseases, including cardiovascular disease. ${ }^{2}$

The health of migrants hangs in the balance between the potential for improved economic circumstances and substandard conditions with unhealthy lifestyles in low-income urban communities. International migration from LMIC to highincome countries has been associated with decreased all-cause mortality in comparison with the native-born population of the same nationality. ${ }^{3}$ Yet the mortality impact of urbanisation and within-country migration from rural communities to urban centres in LMIC has not been well described.

The primary objective of this study was to compare all-cause and cause-specific mortality among three distinct groups: within-country rural-to-urban migrants, rural dwellers and urban dwellers.

\section{METHODS}

\section{Study design and setting}

The PERU MIGRANT Study was designed to evaluate risk factors for cardiovascular disease in three population groups: urban dwellers in Pampas de San Juan de Miraflores, a shanty town community in Lima; rural dwellers in two communities (San Jose de Secce and Chacas) located in Ayacucho, Peru; and rural-to-urban migrants from Ayacucho to Pampas de San Juan de Miraflores. An age-stratified and sex-stratified sampling frame from each population group was identified using household census data. ${ }^{4}$ Randomly selected participants underwent a questionnaire and anthropometric measurements at a baseline evaluation in 2007$2008^{5}$ and a follow-up visit in 2012-2013.

\section{Participants}

For all study groups, individuals from both sexes aged 30 years and over were considered eligible at baseline. Pregnant women and those with mental disorders precluding voluntary participation were excluded.

\section{Mortality}

Date and cause of death were determined by death certificates. When death certificates were not available, the participant's relatives were interviewed to verify mortality and causes. All-cause and specificcause mortality information was grouped according to standardised definitions (see online supplementary file 1).

\section{Study variables at baseline}

Cardiovascular risk factors were determined using the baseline data from the PERU MIGRANT study. Hypertension was defined as systolic blood pressure (SBP) $\geq 140 \mathrm{~mm} \mathrm{Hg}$; diastolic blood pressure (DBP) 
$\geq 90 \mathrm{~mm} \mathrm{Hg}$; or by self-report of physician diagnosis with concomitant use of antihypertensive medications. ${ }^{6}$ Diabetes was defined as fasting capillary blood glucose $\geq 126 \mathrm{mg} / \mathrm{dL}$, or a selfreport of physician diagnosis. ${ }^{8}$ High total cholesterol was defined as fasting cholesterol $\geq 200 \mathrm{mg} / \mathrm{dL}^{9}{ }^{9}$ and obesity was defined as a BMI $\geq 30 \mathrm{~kg} / \mathrm{m}^{2}$.

Tobacco use was defined as having smoked at least one cigarette in the 6 months prior to the interview. Physical activity was assessed with the International Physical Activity Questionnaire. Categorisation of this variable included total days of physical activity and metabolic equivalents ( $\mathrm{min} /$ week) according to international standards. ${ }^{10}$ Alcohol use was defined as the selfreport consumption of $\geq 6$ drinks on the same occasion at least once per month. Education was categorised by schooling years ( $<6,7-11$ and $\geq 12$ years). Socioeconomic status was measured using a wealth index based on household income, assets and household facilities separately for each study group, ${ }^{11}$ and then combined into a single variable.

\section{Statistical methods}

Statistical analyses were conducted in STATA V.12 (STATA Corp, College Station, USA). Non-standardised mortality rates per 1000 person-years were calculated. The association between migration status and all-cause and specific-cause mortality was estimated using Cox proportional hazards regression analyses reporting crude and adjusted models. Multivariable models were created using a hierarchical approach: ${ }^{12}$ model 1 included age and sex as confounders, whereas model 2 also included education and the assets index. Since rurality is highly associated with lower education and socioeconomic status, collinearity was assessed using the VIF command in STATA.

\section{Ethical approval}

Ethical approval was obtained from the Ethics Committee at Universidad Peruana Cayetano Heredia in Peru under the ID 60014 dated 21 June 2012. Participants provided verbal informed consent due to major illiteracy rates, especially in rural areas.

\section{RESULTS}

\section{Population characteristics}

A total of 928 of the 989 participants included at baseline (94\% follow-up rate) were evaluated. At baseline, the mean age was 48 years and $53 \%$ of the cohort was female. After a mean follow-up time of 5.1 years (4732.8 person-years), in total there were 33 deaths ( 9 attributable to cardiovascular causes and 8 to cancer). Older age, male sex, low education, low asset index, and hypertension prevalence were characteristics associated with greater mortality during the follow-up period (table 1).

\section{Mortality patterns}

In general, all-cause mortality rates were similar between rural and urban groups, but these rates were halved in the migrant group. When evaluated by specific causes of death, cardiovascular and cancer deaths occurred predominantly in the urban group, whereas infectious diseases mortality was predominant in rural dwellers (see online supplementary file 2).

Table 2 shows HRs for mortality by study group, using the urban group as a reference, and after adjustment for potential confounders. For all-cause mortality, there was evidence of lower mortality in the rural group only, by an order of $73 \%$. In terms of cardiovascular mortality, both the migrant and rural groups had lower mortality, $87 \%$ and $93 \%$ reduction, respectively, and HRs were not different between these two groups.
Table 1 Baseline characteristics of the PERU MIGRANT Cohort Study by incident all-cause mortality

\begin{tabular}{|c|c|c|c|}
\hline & $\begin{array}{l}\text { Dead } \\
(n=33) \\
N(\%)\end{array}$ & $\begin{array}{l}\text { Alive } \\
(n=895) \\
N(\%)\end{array}$ & p Value* \\
\hline Age (years) & & & $<0.01$ \\
\hline $30-39$ & $3(1.1)$ & $259(98.8)$ & \\
\hline $40-49$ & $1(0.4)$ & $263(99.6)$ & \\
\hline $50-59$ & $7(2.7)$ & $252(97.3)$ & \\
\hline $60+$ & $22(15.4)$ & $121(84.6)$ & \\
\hline Sex & & & 0.005 \\
\hline Female & $11(2.2)$ & $482(97.8)$ & \\
\hline Male & $22(5.1)$ & $413(94.9)$ & \\
\hline Site/migration status & & & 0.07 \\
\hline Rural & $10(5.0)$ & $191(95.0)$ & \\
\hline Migrant & $14(2.6)$ & $526(97.4)$ & \\
\hline Urban & $9(4.8)$ & 178 (95.2) & \\
\hline Education & & & 0.01 \\
\hline Primary school or less & $24(5.3)$ & $430(94.7)$ & \\
\hline Secondary school or more & $9(1.9)$ & $463(98.1)$ & \\
\hline Asset index (tertiles) & & & 0.02 \\
\hline Lowest & $19(5.7)$ & $313(94.3)$ & \\
\hline Middle & $8(2.7)$ & $294(97.4)$ & \\
\hline Highest & $6(2.0)$ & $288(96.4)$ & \\
\hline Current smoking & & & 0.11 \\
\hline Yes & $6(6.0)$ & $94(94.0)$ & \\
\hline No & $27(3.3)$ & $801(96.7)$ & \\
\hline Alcohol use & & & 0.77 \\
\hline High & $3(3.9)$ & 75 (96.2) & \\
\hline Low & $30(3.5)$ & 820 (96.5) & \\
\hline Physical activity & & & 0.69 \\
\hline Low & $10(4.2)$ & $231(95.8)$ & \\
\hline Moderate/high & $23(3.4)$ & $656(96.6)$ & \\
\hline $\begin{array}{l}\text { High total cholesterol (>200 mg/ } \\
\mathrm{dL} \text { ) }\end{array}$ & & & 0.008 \\
\hline Yes & $5(1.7)$ & $281(98.3)$ & \\
\hline No & $28(4.4)$ & 613 (95.6) & \\
\hline Obesity (BMI $\geq 30 \mathrm{~kg} / \mathrm{m}^{2}$ ) & & & 0.28 \\
\hline Yes & $5(2.6)$ & 185 (97.4) & \\
\hline No & $28(3.8)$ & 710 (96.2) & \\
\hline Hypertension & & & 0.0001 \\
\hline Yes & $13(8.6)$ & 138 (91.4) & \\
\hline No & $20(2.6)$ & 756 (97.4) & \\
\hline Diabetes & & & 0.55 \\
\hline Yes & $2(5.1)$ & 37 (94.9) & \\
\hline No & $31(3.5)$ & 857 (96.5) & \\
\hline
\end{tabular}

* Log rank test for equality of survivor functions. BMI, body mass index.

While results for cancer mortality tended towards lower mortality among migrant and rural groups, CIs spanned 1.

\section{DISCUSSION}

In a longitudinal cohort of three population groups in Peru, rural dwellers were at lower risk of all-cause mortality when compared with urban dwellers. Additionally, a pattern of risk reduction was also seen in migrant individuals. Interestingly, both migrant and rural participants showed lower (around 90\% reduction) cardiovascular mortality than their urban counterparts, and there was a trend towards lower cancer-related mortality. 
Table 2 Population group as a risk factor for all-cause, cardiovascular-related and cancer-related mortality

\begin{tabular}{|c|c|c|c|}
\hline & $\begin{array}{l}\text { Crude model } \\
\text { HR }(95 \% \mathrm{Cl})\end{array}$ & $\begin{array}{l}\text { Model } 1 \\
\text { HR (95\% Cl) }\end{array}$ & $\begin{array}{l}\text { Model } 2 \\
\text { HR (95\% Cl) }\end{array}$ \\
\hline \multicolumn{4}{|c|}{ All-cause mortality } \\
\hline Urban & 1 (Reference) & 1 (Reference) & 1 (Reference) \\
\hline Migrant & 0.46 (0.19 to 1.08$)$ & 0.44 (0.18 to 1.04$)$ & 0.30 (0.12 to 0.78$)$ \\
\hline Rural & 1.07 (0.43 to 2.62$)$ & 0.90 (0.36 to 2.23 ) & 0.49 (0.16 to 1.43$)$ \\
\hline \multicolumn{4}{|c|}{ CV mortality } \\
\hline Urban & 1 (Reference) & 1 (Reference) & 1 (Reference) \\
\hline Migrant & $0.11(0.02$ to 0.57$)$ & $0.11(0.02$ to 0.54$)$ & 0.07 (0.01 to 0.41$)$ \\
\hline Rural & $0.16(0.02$ to 1.32$)$ & $0.12(0.01$ to 1.03$)$ & $0.06(0.01$ to 0.62$)$ \\
\hline \multicolumn{4}{|c|}{ Cancer mortality } \\
\hline Urban & 1 (Reference) & 1 (Reference) & 1 (Reference) \\
\hline Migrant & 0.86 (0.17 to 4.42$)$ & 0.84 (0.16 to 4.32 ) & 0.67 (0.11 to 4.04$)$ \\
\hline Rural & $0.48(0.04$ to 5.30$)$ & $0.41(0.04$ to 4.51$)$ & $0.29(0.02$ to 4.11$)$ \\
\hline \multicolumn{4}{|c|}{ NCD (CV+cancer) mortality } \\
\hline Urban & 1 (Reference) & 1 (Reference) & 1 (Reference) \\
\hline Migrant & 0.30 (0.11 to 0.83$)$ & 0.28 (0.10 to 0.79$)$ & $0.20(0.07$ to 0.62$)$ \\
\hline Rural & 0.24 (0.05 to 1.12$)$ & $0.19(0.04$ to 0.90$)$ & $0.11(0.02$ to 0.60$)$ \\
\hline \multicolumn{4}{|c|}{$\begin{array}{l}\text { Model 1: adjusted for age and sex. } \\
\text { Model 2: adjusted for age, sex, education and the assets index. } \\
\text { Of the } 928 \text { participants evaluated at follow-up, } 885 \text { had all the variables available to } \\
\text { be included in the multivariable model. } \\
\text { CV, cardiovascular; NCD, non-communicable disease. }\end{array}$} \\
\hline
\end{tabular}

Our previous migration cross-sectional work showed that while the pattern was not uniform for all measured risk factors, overall rural-to-urban migration was associated with a more adverse cardiovascular risk profile: higher levels (urban/ migrants $>$ rural) or a gradient of levels (urban $>$ migrant $>$ rural) was observed for common cardiovascular risk factors including BMI, lipid profile, metabolic and inflammatory markers, but not blood pressure. ${ }^{5}$ This follow-up study demonstrates that although rural-to-urban migrants had increased risk factors compared to the rural group at baseline, their mortality remained similar to that of rural dwellers: migrants did not seem to 'catch up' with the urban group in spite of taking on a more urban cardiovascular risk profile. We hypothesize that rural-to-urban migrants do not develop the full urban mortality risk because of healthier lifestyles early in life.

Given the trend of increasing urbanisation in LMIC, the association between a lifelong urban shanty town residence and all-cause mortality is a matter of concern for public health. While the health hazards of urban shanty towns have been well described, ${ }^{1}{ }^{13}$ studies of the health of within-country migrants across the globe have had conflicting results, suggesting that at times the benefits of urban migration, including better access to education, health services and nutrition, translate into better health outcomes in comparison with individuals who remain in rural poverty. ${ }^{14}$

Additionally, transnational migration from LMIC to highincome countries has been associated with decreased all-cause mortality when compared with native-born populations of the same nationality, widely referred to as the healthy migrant effect. ${ }^{3}$ Most of these studies lack a non-migrant site-of-origin comparison group hence, we do not know if, and to what extent, such an effect is an artefact. In our study, we benefited from having two reference populations to compare the migrant group with, showing that cardiovascular mortality was lower in the migrant group relative to the urban group. This means that despite their current urban residence status, migrants still bear some of the 'benefits' of lower rural mortality.
This study benefits from its prospective nature and the use of three well-defined populations. However, this study also has limitations. The results of this study are limited by the small sample size as well as the limited number of deaths in the follow-up period, thus resulting in point estimates with wide CIs. In addition, the cause of death determination was limited to death certificates and family report. Classification bias may arise due to methods used to determine the cause of death, particularly in rural areas, as potential interpretation of death and its causes could have influenced the report. However, we believe that our results regarding mortality were not affected.

In conclusion, cardiovascular mortality of migrants was similar to that of the rural group, suggesting that rural-to-urban migrants do not appear to catch up with the urban mortality despite having a more adverse cardiovascular risk factor profile similar to the urban population. Given the global trend of increasing urbanisation, resources should be mobilised to understand and address the negative health outcomes associated with residing in urban slum communities in LMIC, as well as to improve our understanding of the protective factors that lower mortality observed in migrants.

\section{What is already known on this subject?}

Urban lifestyles increase the risk of chronic diseases, including cardiovascular disease: the health of migrants hangs in the balance between the potential for improved economic circumstances and the reality of substandard conditions with unhealthy lifestyles in low-income urban communities.

\section{What this study adds?}

- Most of the studies of the impact of migration on mortality lack a non-migrant site-of-origin comparison group.

- Both migrant and rural participants showed $90 \%$ reduction in cardiovascular mortality when compared with their urban counterparts.

\section{Author affiliations}

${ }^{1}$ CRONICAS Centre of Excellence in Chronic Diseases, Universidad Peruana Cayetano Heredia, Lima, Peru

2Duke University Research Institute, Duke University, Durham, North Carolina, USA ${ }^{3}$ Department of Parasitology, U.S. Naval Medical Research Unit No.6 (NAMRU-6), Callao, Peru

${ }^{4}$ Medical School, University College London, London, UK

${ }^{5}$ Department of Medicine, School of Medicine, Universidad Peruana Cayetano Heredia, Lima, Peru

${ }^{6}$ Program in Global Disease Epidemiology and Control, Department of International Health, Bloomberg School of Public Health, Johns Hopkins University, Baltimore, Maryland, USA

${ }^{7}$ Biomedical Research Unit, Asociación Benéfica PRISMA, Lima, Peru

${ }^{8}$ Faculty of Epidemiology and Population Health, London School of Hygiene and Tropical Medicine, London, UK

Correction notice This article has been corrected since it published Online First. The results section of the abstract has been revised.

Acknowledgements Professor Héctor H García provided direct advice for the various phases for the establishment of the study in Peru. Our special gratitude to various colleagues at Universidad Peruana Cayetano Heredia and A.B. PRISMA in Lima, Peru and several others in the UK, as well as to the staff and the team of fieldworkers that contributed to different parts of this study. Most importantly, our 
sincere gratitude is extended to the people who agreed to take part in the study. Special acknowledgements to Candice Romero and Lilia Cabrera who coordinated the baseline fieldwork phase of this study, and to Julio Poterico for his support in planning and coordinating the follow-up phase of the study.

Contributors MSBP, AB-O and JJM defined the analysis plan of this manuscript. $A B-O$ led the statistical analysis. JFS and RQ coordinated and supervised the fieldwork activities in Lima and Ayacucho. AB-0, JFS and JJM developed the idea for this manuscript. MSBP wrote the initial draft of the manuscript, and all authors participated in the writing of the manuscript and approved the final version.

Funding The PERU MIGRANT Study baseline assessment work was funded through a Wellcome Trust Master Research Training Fellowship and a Wellcome Trust PhD Studentship to JJM (074833), and its follow-up by Universidad Peruana Cayetano Heredia (Fondo Concursable No. 20205071009). RMC-L, AB-O and JJM and the CRONICAS Centre of Excellence in Chronic Diseases were supported by Federal funds from the United States National Heart, Lung, and Blood Institute, National Institutes of Health, Department of Health and Human Services, under contract No. HHSN268200900033C. LS is a Wellcome Trust Senior Clinical Fellow (098504/Z/12/Z), and AB-O is a Wellcome Trust Research Training Fellow in Public Health and Tropical Medicine (103994/Z/14/Z).

Competing interests None declared.

Patient consent Obtained.

Ethics approval Universidad Peruana Cayetano Heredia.

Provenance and peer review Not commissioned; externally peer reviewed.

Data sharing statement Data of the original PERU MIGRANT Study (baseline) were published in Heart. Other papers of the baseline have been published in different journals. Three papers have been written using information of the study follow-up. Data can be made available upon request from authors.

\section{REFERENCES}

1 World Health Organization. A billion voices: listening and responding to the health needs of slum dwellers and informal settlers in new urban settings. Kobe: World Health Organization, 2005.
2 Patel RB, Burke TF. Urbanization—an emerging humanitarian disaster. N Engl J Med 2009;361:741-3.

3 Singh GK, Miller BA. Health, life expectancy, and mortality patterns among immigrant populations in the United States. Can J Public Health 2004;95:114-21.

4 Miranda JJ, Gilman RH, Garcia HH, et al. The effect on cardiovascular risk factors of migration from rural to urban areas in Peru: PERU MIGRANT Study. BMC Cardiovasc Disord 2009;9:23.

5 Miranda JJ, Gilman RH, Smeeth L. Differences in cardiovascular risk factors in rural, urban and rural-to-urban migrants in Peru. Heart 2011;97:787-96.

6 Chobanian AV, Bakris GL, Black HR, et al. The Seventh Report of the Joint National Committee on prevention, detection, evaluation, and treatment of high blood pressure: the JNC 7 report. JAMA 2003;289:2560-72.

7 Expert Committee on the Diagnosis and Classification of Diabetes Mellitus. Report of the expert committee on the diagnosis and classification of diabetes mellitus. Diabetes Care 2003;26(Suppl 1):S5-20.

8 American Diabetes Association. Diagnosis and classification of diabetes mellitus. Diabetes Care 2005;28(Suppl 1):S37-42.

9 National Cholesterol Education Program (NCEP) Expert Panel on Detection, Evaluation, and Treatment of High Blood Cholesterol in Adults (Adult Treatment Panel III). Third Report of the National Cholesterol Education Program (NCEP) Expert Panel on Detection, Evaluation, and Treatment of High Blood Cholesterol in Adults (Adult Treatment Panel III) final report. Circulation 2002;106:3143-421.

10 Office of Disease Prevention and Health Promotion. Department of Health and Human Services. 2008 Physical Activity Guidelines for Americans. Washington DC: DHHS, 2008.

11 Howe LD, Galobardes B, Matijasevich A, et al. Measuring socio-economic position for epidemiological studies in low- and middle-income countries: a methods of measurement in epidemiology paper. Int J Epidemiol 2012;41:871-86.

12 Victora CG, Huttly SR, Fuchs SC, et al The role of conceptual frameworks in epidemiological analysis: a hierarchical approach. Int J Epidemiol 1997;26: 224-7.

13 World Health Organization. Our cities, our health, our future: acting on social determinants for health equity in urban settings. Kobe City: World Health Organization, 2008.

14 McKay L, Macintyre S, Ellaway A. Migration and health: a review of the international literature. Glasgow: University of Glasgow, 2003:206. 